\title{
The national Reading Recovery data as a possible indicator of reading progress for six-year-olds in New Zealand:
}

\section{Some issues}

\author{
Dr Keith Greaney
}

Senior Lecturer, Department of Learning and Teaching in the College of Education, Massey University

\begin{abstract}
Apart from the annual returns to the Ministry of Education of Reading Recovery (RR) data (and to a lesser extent, the four-yearly National Education Monitoring Project cycle data), there is currently no national data sets of reading achievement information for New Zealand primary school children. This article uses the national RR data for 2002 as a basis for estimating the likely full extent to which 6 -year-olds may be underachieving in reading after one year of instruction. For the purposes of this article, average or above' achievement in reading after one year at school is defined as being able to read at or above book level 12 and being able to correctly read 20 or more words from the Burt Word reading test. To gain a wider perspective of reading performance at age six years, the six-year net data from three large urban schools for the years 2000 to 2004 was also analysed. The results show that although some researchers suggest that only two percent of children require extra reading tuition following $R R$, this figure is probably not a true indicator of the extent of early reading problems.

\section{Research paper}

KEYWORDS:
\end{abstract}

Reading Recovery, reading achievement, reading disabilities, data collection.

\section{INTRODUCTION}

Progress through the early reading stages in New Zealand primary schools has for many years been represented by 'book levels'. Following the introduction of the Ready to Read series of books, these levels have also been represented by colours on a 'colour wheel'. The colour wheel is divided into nine colours and each colour band equates to reading level bands, from the emergent, pre-reading level to the equivalent of a reading age of 7.5 to 8 years. While there may be many different ways to represent early reading progress, McNaughton, Phillips and MacDonald (2000) note that 'reading level is the most significant of the criteria that could be employed for judging early progress within the channel afforded by the curriculum' (p. 50). Their reason being that the specifications of the curriculum value reading so highly and that 'text levels more than any other measures of progress or achievement reflect the co-construction of development' (p. 50). Teachers also use text level placements as a basis of promotion in their general class reading programmes and for reporting general reading progress to parents and caregivers.
In relation to reading ability, what is the current accepted norm for 'average' reading progress for a child who has been at school for one year? In a recently published reading text, the Ministry of Education (2003) gives a 'ball-park' indication when it states that 'There is a widely held expectation among teachers that children at the end of year 1 will be reading at (or beyond) Blue to Green levels on the Ready to Read colour wheel' ( $p$. 71). The Blue to Green levels equate with book levels nine to 14 which in turn, equate with a reading age of approximately six years. Using the Blue/Green levels as a barometer for average progress, many schools use a book level per month as a basic performance indicator for average reading progress over the first year. Following this barometer, these schools would normally expect children to reach at least level 12 by the end of their first year of reading instruction. Indeed, Anand and Bennie (2004) note that the majority of children who were enrolled in RR in 2002 were reading at or below book level five on entry to the programme.

This article uses the 2002 national RR data (Anand \& Bennie, 2004) as a basis for estimating the number and percentage of all children who may be failing to develop satisfactory reading progress after one year of school. This is used because it is currently the only set of data that gives a nationwide picture of reading ability for a particular cohort of children, in this case, six-year-olds. The RR data is only concerned with RR enrolment information so this article also attempts to show how many other six-year-olds may also be showing limited progress in reading after one year at school.

\section{THE 2002 RR DATA}

Table 1 shows the percentage of schools that offered RR programmes in 2002 and the percentage of all six-year-old children who were taking part in the programmes during that year.

TABLE 1

RR participants in 2002 (including 'carried-over' pupils from 2001) as a function of the total six-year-old population

\begin{tabular}{llll}
\hline $\begin{array}{l}\text { Total } \\
\text { six-year-old } \\
\text { Population }\end{array}$ & $\begin{array}{l}\text { Total in RR } \\
\text { Programmes }\end{array}$ & $\begin{array}{l}\text { Percentage } \\
\text { of all } \\
\text { six-year-olds }\end{array}$ & $\begin{array}{l}\text { Percentage } \\
\text { of Schools } \\
\text { with RR } \\
\text { Programmes }\end{array}$ \\
\hline 55,200 & 11,565 & $21 \%$ & $67.8 \%$ \\
\hline
\end{tabular}


TABLE 2

RR participant data plus estimated numbers of additional at-risk six-year-old readers (from 'non-RR' schools) for 2002

\begin{tabular}{llllll}
$\begin{array}{l}\text { Total six-year-old } \\
\text { population }\end{array}$ & Total in RR & $\begin{array}{l}\text { Percent of Schools } \\
\text { without RR }\end{array}$ & $\begin{array}{l}\text { Estimated 'missing' } \\
\text { children at-risk }\end{array}$ & $\begin{array}{l}\text { New estimated } \\
\text { at-risk total }\end{array}$ & $\begin{array}{l}\text { New estimated } \\
\text { at-risk percentage }\end{array}$ \\
\hline 55,200 & 11,565 & $32.2 \%$ & 5,781 & 17,343 & $31.4 \%$ \\
\hline
\end{tabular}

TABLE 3

Frequency and percent (by gender and school) of below average Burt Words and book reading levels for six-year net results for three urban schools 2000-2004

\begin{tabular}{|c|c|c|c|c|c|c|}
\hline & \multicolumn{2}{|c|}{ Below Level 12} & \multicolumn{2}{|c|}{ Below 20 Burt Words } & \multicolumn{2}{|c|}{$\begin{array}{l}\text { Combined Less Than Book } \\
\text { Level } 12 \& 20 \text { Burt Words }\end{array}$} \\
\hline & Total & Percent & Total & Percent & Total & Percent \\
\hline \multicolumn{7}{|l|}{ School A } \\
\hline Boys $(n=85)$ & 40 & $47 \%$ & 38 & $44 \%$ & 35 & $41 \%$ \\
\hline Girls (n=95) & 24 & $25 \%$ & 22 & $23 \%$ & 20 & $21 \%$ \\
\hline \multicolumn{7}{|l|}{ School B } \\
\hline Boys $(n=87)$ & 65 & $74 \%$ & 49 & $56 \%$ & 47 & $54 \%$ \\
\hline Girls $(n=72)$ & 39 & $54 \%$ & 33 & $45 \%$ & 32 & $44 \%$ \\
\hline \multicolumn{7}{|l|}{ School C } \\
\hline Boys $(n=59)$ & 43 & $72 \%$ & 38 & $64 \%$ & 38 & $64 \%$ \\
\hline Girls $(n=55)$ & 30 & $54 \%$ & 23 & $41 \%$ & 23 & $41 \%$ \\
\hline
\end{tabular}

TABLE 4

Totals for below average readers (Burt Words and book levels) by gender for all schools combined

\begin{tabular}{|c|c|c|c|c|c|c|}
\hline & \multicolumn{2}{|c|}{ Below Level 12} & \multicolumn{2}{|c|}{ Below 20 Burt Words } & \multicolumn{2}{|c|}{$\begin{array}{l}\text { Combined Less Than Book } \\
\text { Level } 12 \& 20 \text { Burt Words }\end{array}$} \\
\hline & Total & Percent & Total & Percent & Total & Percent \\
\hline \multicolumn{7}{|l|}{ School A } \\
\hline Boys ( $n=231)$ & 148 & $64 \%$ & 125 & $54 \%$ & 120 & $51 \%$ \\
\hline Girls (n=222) & 93 & $41 \%$ & 78 & $35 \%$ & 75 & $33 \%$ \\
\hline
\end{tabular}

When 'carried over' pupils from 2001 are included, the data show that there were 11,565 pupils who were taking part in RR programmes in 2002. This total represents 21 percent of the total six-year-old population in New Zealand. Table 1 also shows that RR was available in 67 percent of all schools suggesting that there is still a significant group of children with early reading problems who are not accounted for in RR statistics. The data in Table 2 offers a likely estimate of the remaining six-year-old population who are not accounted for in the RR statistics but who may still have significant early reading problems.

In 2002, the 67 percent of schools who did have RR attracted 11,565 participants in this programme, the new enrolments plus those carried over. This represented 21 percent of the total six-year-old population for that year. However, the data in Table 2 suggest that the 32 percent of schools in 2002 who did not have access to RR would most likely also have an additional 5,781 children who would have required extra reading assistance in a $\mathrm{RR}$ programme had such a programme been available. This new figure is gained by assuming that because 11,565 enrolments were generated from only two thirds of the potential schools, the remaining one third of schools should, in all probability, also generate the remaining one third of the total, which is 5,781. Based on these figures it could therefore be assumed that had RR been available across all schools in 2002, the new total of at-risk six-year-old children requiring the extra reading instruction would have been approximately 17,343 . This new total represents at least 31 percent of the total six-year-old population in that year.

Remembering that this new estimated total of low-achieving six-year-old children is based only on the 2002 RR data, even this does not necessarily present the full extent of the probable reading disability figures. When RR is available in a particular school, it doesn't necessarily follow that all needy children are 'picked up' in this programme. This is because in most cases a RR teacher is funded to only take a maximum of four children at any one time. This often means that in larger schools, there are frequently other low-achieving readers who may require extra tuition but are unable to access it because of a lack of available places. An investigation of school-wide six-year net results allows a more accurate insight into the true extent of the reading status of children at age six.

\section{SIX-YEAR NET DATA FROM THREE SCHOOLS}

In order to investigate the reading status of all children at age six, the six-year net results from three urban schools were analysed. RR programmes were also operating in all three schools at the time of the investigation and the data 
reported in Tables 3 and 4 covers 2000 to 2004. While the full six-year net results were available for this analysis, the data discussed here relates only to the book reading levels and the Burt Word scores. The reason for the book level and Burt Word scores' focus is that these two measures more closely represent 'general reading ability' than most of the remaining six-year net measures. The Burt Word test is also a nationally "normed" test and therefore gives more credibility to the general reading ability measure than a book reading level would measure by itself. The results are also analysed by gender.

For this article, a book level score of 12 and a Burt Word score of 20 are used as the expected norm scores for reading achievement after one year of instruction. The data in Tables 3 and 4 present the results from the three schools.

Using book reading level 12 and a Burt Word score of 20 as the expected average scores, the data in Table 3 give some indication of the numbers of children experiencing reading difficulties after one year of instruction in each of the schools. There appears to be a general tendency for more boys than girls to have below average reading scores at age six. There also appears to be lower numbers of both boys and girls achieving below average reading scores in School A compared to the other two schools. In Schools B and C, more than 70 percent of all six-year-old boys were reading below book level 12, whereas only 47 percent of the boys in School A were reading below that level. Similarly, the Burt Word score results also reflected both a gender and school difference. Sixty-four percent of the boys in School C scored below 20 on the Burt Word test compared to 44 percent of the boys in School A. When both the below 12 book reading level and below 20 Burt Word scores were combined, the results show that 64 percent of all the boys in School $C$ and 54 percent of all the boys in School B scored below this combined threshold.

When the data from the three schools are combined and the results presented by gender, it is evident that more than half of all the boys were performing below average on all three measures after one year of school. This data are presented in Table 4.

Sixty-four percent of all the boys in the three schools were reading below book level 12 at age 6 compared with 41 percent of all girls. Fifty four percent of the boys scored below 20 in the Burt Word test compared with 35 percent of the girls. Finally, when the below 12 book level/below 20 Burt Word' measures are combined, 51 percent of all the boys were still performing below the average, compared with 33 percent of the girls.

These results compare closely with those found in a similar study by Hobbs (2001), in which she reported that the mean Burt Word score for her six-year net data for boys was only 16.5. Given that a score of 20 represents average for a sixyear-old, it would be expected that more than half of Hobbs' boys were performing below this level. Similarly the girls' mean Burt Word score in the Hobbs study was also below 20 at 19.7 .

\section{CONCLUSION}

While individual schools collect their own literacy data using various measures, including the six-year net survey data, there is no national data base record for this information. The annual RR data, which is collected from only RR enrolments using the six-year net survey measures, may be used as an approximate indicator of national reading achievement. The annual RR data for 2002 show that 11,565 children were enrolled in this programme and that this figure represented 21 percent of all six-year-olds. However, given that only 60 to 70 percent of all schools have a RR programme operating in any one year the national figure for all children who are showing low progress in reading after one year at school is likely to be considerably higher than 21 percent. There are two main reasons for this:

1. Not all schools have a RR programme. Because the annual RR data is collected only from active RR teachers (and teachers in training), there are still over 30 percent of schools who don't have RR teachers or programmes. Many children in these non-RR schools are failing to make adequate progress after one year at school, and because they are not enrolled in a RR programme, their statistics are not recorded anywhere beyond the school.

2. Not all children are able to access a RR programme even if one is operating in their school. A RR teacher is generally only funded to take a maximum of four children at any one time so there are children who do not access the programme because there is no vacancy at the time. Again, these numbers are not recorded on any national data base.

Using reading book level 12 and a Burt Word score of less than 20 as proxy measures for assessing 'average' reading performance after one year at school, the six-year net data for the period 2000 to 2004 was collected and analysed from three large urban schools. The investigation showed that over 50 percent of all the boys in the three schools and over 30 percent of all girls were performing below the benchmark scores on both measures at six years. In summary, although between 16-21 percent of all six-year-old children require $R R$, the data suggest that this figure does not present an accurate account of the total numbers requiring extra reading assistance. If the data from the three urban schools is transferred on a national base, the total number of children requiring extra reading assistance after one year of school is likely to be in the vicinity of 30 percent for girls and up to 50 percent for boys.

While the purpose of this article was not to discuss the effectiveness or otherwise of the RR programme, it is interesting to note that Phillips and Smith (1997) state that, after completing a RR intervention, there remains a small percentage of children - less than 2 percent, or approximately 1000 each year, who are identified as needing more help than the two prongs can offer' ( $p$. 3). The two 'prongs' being the regular class programme of instruction and RR. The authors base their 2 percent figure only on the number of children who do not succeed in a RR programme. The figure does not take into account the children who do not enter a RR programme in the first place. 
The results from the six-year net data in the three urban schools and the estimated new totals of potential reading failures from the 'non-RR' schools suggests that the numbers of six-year-olds with reading difficulties may be as high as 50 percent.

It is not suggested here that this figure of 50 percent is common for all schools or that it remains at this level throughout the entire schooling system. Many of these six-year-olds who fail in the six-year net may well catch up to their classmates in future years. However, there are still likely to be significant numbers who may continue to have ongoing reading problems if no suitable interventions are given. While nationally, the number of six-year-olds who are failing to make satisfactory reading progress after one year at school may not be as high as 50 percent, it is still likely that substantial numbers will need extra assistance in Year one. Unfortunately, the national RR data that is collected annually by the Ministry of Education, and is currently the only substantial data base on literacy levels for six-year-olds, may mask this issue.

A second major finding from this investigation relates to the significantly higher numbers of boys who were shown to be performing below average in book reading level and Burt Word test scores after one year at school compared to the girls. Some international research evidence claims that there is little or no gender differences in reading ability (Prior, Sanson, Smart \& Oberklaid, 1995; Shaywitz, Shaywitz, Fletcher \& Escobar, 1990). Many of these researchers suggest that the main reason why more boys than girls are often identified by teachers and/or clinicians with reading disabilities is due merely to a selection bias. It is often claimed that this selection bias is attributed more to the type of assessment used to identify reading disabilities than to specific reading disability evidence. Catts and Kamhi (2005) claim for example that 'if a low score on a reading achievement test (and/or a discrepancy between reading and IQ) is used as the primary criterion to identify a reading disability, then one should expect to find about as many girls with reading disabilities as boys' ( $p$. 57). The current study used two measures of reading achievement (book reading level and Burt Word test scores) and yet the data clearly indicate that more boys than girls were underachieving after one year at school. In this case, it appears that the higher numbers of boys enrolled in reading intervention programmes, including RR, may be justified.

Finally, if we are serious about closing the literacy performance 'gap' between the good and poor readers, a stronger effort may be needed from the Ministry of Education to design assessments that more effectively identify the failing readers well before their sixth birthday. Maybe a five-year net assessment needs to be introduced because there seems to be little educational sense in attempting to identify reading problems 12 months 'down the track'. However, such a five-year net would almost certainly need to include different assessments from those currently used.

\section{REFERENCES}

Anand, V. \& Bennie, N. (2004). Annual Monitoring of Reading Recovery: The Data for 2002. Wellington, Ministry of Education.

Catts, H. W., \& Kamhi, A. G. (2005). Language and Reading Disabilities. Second Edition. Boston, Pearson Publications.

Hobbs, M. (2001). Gender, ethnicity and literacy acquisition by Age Six. SET 1, Wellington, New Zealand Council for Educational Research.

McNaughton, S., Phillips, G., \& MacDonald, S. (2000). Curriculum channels and literacy development over the first year of instruction. New Zealand Journal of Educational Studies, 35, 1, 49-59.

Ministry of Education (2003). Effective Literacy Practice in Years 1 to 4. Wellington. Learning Media.

Phillips, G., \& Smith, P. (1997). Closing the Gaps: Literacy for the Hardest- to- Teach. Wellington. New Zealand Council for Educational Research.

Prior, M., Sanson, A., Smart, D., \& Oberklaid, F. (1995). Reading disability in an Australian community sample. Australian Journal of Psychology, 47, 32-37.

Shaywitz, S. E., Shaywitz, B.A., Fletcher, J.M., \& Escobar, M.D. (1990). Prevalence of reading disability in boys and girls. Journal of the American Medical Association, 264, 998-1102.

\section{AUTHOR PROFILE}

Dr Keith Greaney is a senior lecturer in the Department of Learning and Teaching at Massey University College of Education. Before coming to Massey, Keith was a primary school teacher for 28 years, including two years as a special class teacher and 12 years as a resource teacher reading. $\mathrm{He}$ is also a trained Reading Recovery teacher. Keith teaches a paper in the post graduate Diploma in Literacy Education course and assists with the supervision of students undertaking Masterate research in literacy-related areas.

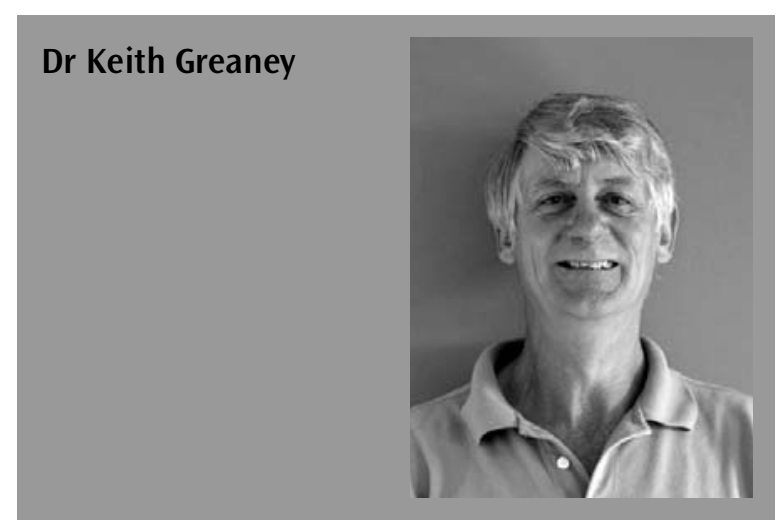

